\title{
Correction to: Recent advances in Surface Guided Radiation Therapy
}

\author{
P. Freislederer ${ }^{1 *}$, M. Kügele ${ }^{2,3}$, M. Öllers ${ }^{4}$, A. Swinnen ${ }^{4}$, T.-O. Sauer ${ }^{5}$, C. Bert ${ }^{5}$, D. Giantsoudi ${ }^{6}$, S. Corradini ${ }^{1}$ and \\ V. Batista ${ }^{7,8,9}$
}

\section{Correction to: Radiat Oncol 15, 187 (2020) https://doi.org/10.1186/s13014-020-01629-w}

Following publication of the original article [1], the authors identified an error in the order of Figs. 2 and 3. The correct representation of figures is provided below.

The original article [1] has been corrected.

\begin{abstract}
Author details
'Department of Radiation Oncology, University Hospital, LMU Munich, Munich, Germany. ${ }^{2}$ Department of Hematology, Oncology and Radiation Physics, Skåne University Hospital, Lund, Sweden. ${ }^{3}$ Medical Radiation Physics, Department of Clinical Sciences, Lund University, Lund, Sweden. ${ }^{4}$ Maastricht Radiation Oncology (MAASTRO), Maastricht, the Netherlands. ${ }^{5}$ Department of Radiation Oncology, Universitätsklinikum Erlangen, Friedrich-Alexander-Universität Erlangen-Nürnberg (FAU), Erlangen, Germany. ${ }^{6}$ Department of Radiation Oncology, Massachusetts General Hospital and Harvard Medical School, Boston, USA. 'Department of Radiation Oncology, Heidelberg University Hospital, Heidelberg, Germany. ${ }^{8}$ Heidelberg Institute of Radiation Oncology (HIRO), Heidelberg, Germany. ${ }^{9}$ National Center for Tumor diseases (NCT), Heidelberg, Germany.
\end{abstract}

Published online: 24 October 2020

\section{Reference}

1. Freislederer, et al. Recent advanced in Surface Guided Radiation Therapy. Radiat Oncol. 2020;15:187. https://doi.org/10.1186/s13014-020-01629-w..

The original article can be found online at https://doi.org/10.1186/s13014020-01629-w.

* Correspondence: philipp.freislederer@med.uni-muenchen.de

'Department of Radiation Oncology, University Hospital, LMU Munich, Munich, Germany

Full list of author information is available at the end of the article

(c) The Author(s). 2020 Open Access This article is licensed under a Creative Commons Attribution 4.0 International License, which permits use, sharing, adaptation, distribution and reproduction in any medium or format, as long as you give appropriate credit to the original author(s) and the source, provide a link to the Creative Commons licence, and indicate if changes were made. The images or other third party material in this article are included in the article's Creative Commons licence, unless indicated otherwise in a credit line to the material. If material is not included in the article's Creative Commons licence and your intended use is not permitted by statutory regulation or exceeds the permitted use, you will need to obtain permission directly from the copyright holder. To view a copy of this licence, visit http://creativecommons.org/licenses/by/4.0/ The Creative Commons Public Domain Dedication waiver (http://creativecommons.org/publicdomain/zero/1.0/) applies to the data made available in this article, unless otherwise stated in a credit line to the data. 

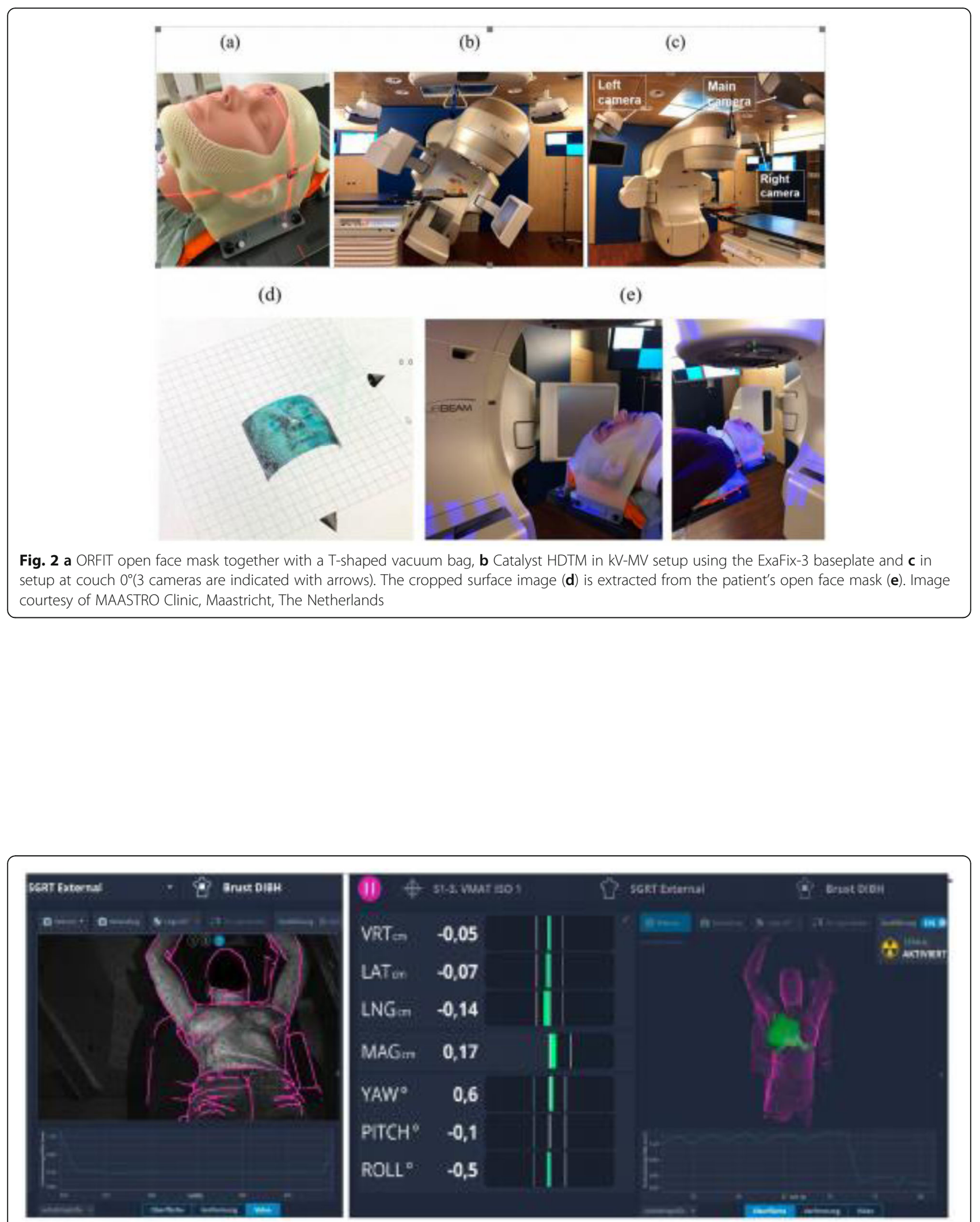

Fig. 3 Positioning of a DIBH patient. Left: Positioning of the patient using the reference surface (purple) and the live surface data. Right: Monitoring of the DIBH during treatment on a highlighted (green) ROI. The breathing curve is depicted on the bottom. Image courtesy of Heidelberg University Hospital, Germany 